\title{
Plasma enteroglucagon and neurotensin in infantile pyloric stenosis
}

\author{
N D CHRistofides, E MALlet, M A GHATEI, Y LEE, AND S R BLOOM \\ Department of Medicine, Royal Postgraduate Medical School, London, and Department of Paediatrics, \\ Charles-Nicolle Hospital and University of Rouen, Rouen, France
}

SUMMARY Plasma concentrations of gastrin, somatostatin, neurotensin, and enteroglucagon were measured by radioimmunoassay in normal 30- and 45-day-old neonates and age-matched infants with confirmed idiopathic hypertrophic pyloric stenosis. Plasma gastrin and somatostatin concentrations were similar in both groups, whereas neurotensin and enteroglucagon were significantly lower in the pyloric stenosis group.

Since the original anatomical description of hypertrophic pyloric stenosis, this disorder has been recognised as the most common congenital anomaly of the gastrointestinal tract requiring surgical correction. The aetiology of the condition is still unknown. Although various hypotheses have been suggested recent interest has been focused on the gastrointestinal hormone gastrin. It is not however agreed whether plasma gastrin is raised in infant pyloric stenosis. $^{1-4}$

Apart from gastrin, other gastrointestinal hormones have received little attention. In the present study ${ }^{\prime}$ we have investigated the concentrations of neurotensin, enteroglucagon, somatostatin, as well as gastrin in infants with pyloric stenosis.

Neurotensin is a newly discovered vasoactive peptide, ${ }^{5}$ which was first found in the synaptosomal and microsomal subcellular fractions of brain tissue, suggesting a role as a central neurotransmitter. ${ }^{6}$ However, in the distal small intestine, neurotensin is located in specific endocrine cells, ${ }^{7}$ indicating a possible role as a gut hormone. The development of a radioimmunoassay ${ }^{8}$ has shown that plasma neurotensin levels rise post-prandially in adults, suggesting a possible role in post-digestive physiology. Although the physiological functions of neurotensin are not fully defined, it has been recently reported that it inhibits gastric motility and gastric acid secretion ${ }^{9}$ and stimulates bicarbonate output by the pancreas. ${ }^{10}$

Enteroglucagon is an intestinal hormonal peptide first discovered as a cross-reacting substance in acid alcohol extracts of human small intestines using early radioimmunoassays for pancreatic glucagon. ${ }^{11}$ Human enteroglucagon has yet to be purified; therefore a study of its physiological actions by exogenous administration has not been undertaken. Some indication of its biological actions comes from the study of a single patient with a renal tumour producing enteroglucagon in high concentrations. ${ }^{12}$ This patient presented with gross villous hypertrophy and slow intestinal transit time, changes which disappeared after resection of the tumour and after the circulating enteroglucagon concentrations had become normal. Other, indirect evidence also suggests enteroglucagon may have a role as a growth factor of the gut. This includes study of gut hypertrophy in experimental animals (for example, after gut resection and hyperphagia of cold adapted rats, in which an increase in enteroglucagon levels correlated closely with the intestinal crypt cell production rate ${ }^{13}$ ).

In man many conditions which tend to cause malabsorption of food are associated with high circulating enteroglucagon and neurotensin. However, both enteroglucagon and neurotensin are low in starvation, where there is gut atrophy. ${ }^{14}$ Concentrations are also low in cord blood and rise sharply after oral nutrition, although they remain low in infants who are not enterally fed. ${ }^{15}$

Somatostatin is another peptide that was first discovered in the brain ${ }^{16}$ and subsequently found to occur in the gastrointestinal tract. Infusion of somatostatin into humans has shown that pharmacologically the peptide possesses powerful inhibitory effects on a number of diverse physiological functions, ${ }^{17}$ including gastric and pancreatic secretions.

\section{Patients and methods}

Twelve term infants, without gastrointestinal disease 
( 6 each at 30 and 45 days post-partum) and 12 term infants with pyloric stenosis (6 each at $31 \pm 1.6$ and $44 \pm 3$ days post-partum) were studied with the approval of the ethics committee. The weights of the infants at the time of sampling (before the operation) were comparable (controls and pyloric stenosis at 30 days, $4 \pm 0.3$ and $4 \pm 0.2 \mathrm{~kg}$, and at 45 days $4.5 \pm 0.3$ and $4.3 \pm 0.2 \mathrm{~kg}$ respectively). Also, birthweights in the two groups were not different (control, $3 \cdot 6 \pm 0 \cdot 2 \mathrm{~kg}$ and pyloric stenosis $3 \cdot 7 \pm 0 \cdot 1$ $\mathrm{kg})$. The mean daily food intake in the two groups were: control, $184 \pm 9 \mathrm{ml} / \mathrm{kg}$, pyloric stenosis, $143 \pm 6 \mathrm{ml} / \mathrm{kg}, \mathrm{P}<0.005)$.

The diagnosis of pyloric stenosis was made on clinical history (vomiting and constipation) and by radiological examination; the diagnosis was confirmed at operation. The duration of the symptoms was for a mean of $5 \pm 1$ days.

All infants were 'formula fed' (Guigoz) at 4-hourly intervals. In each group samples were taken immediately before feeding.

All the blood was taken before operation. Venous blood samples $(2 \mathrm{ml})$ were collected into heparincoated tubes containing approtinin (Trasylol, Bayer: $2000 \mathrm{KIU}$ ); the plasma was separated after centrifugation at $4^{\circ} \mathrm{C}$ within 20 minutes of collection. All samples were stored at $-20^{\circ} \mathrm{C}$ until assay. Plasma neurotensin was measured by radioimmunoassay as previously described, ${ }^{8}$ with some modifications and using a new antibody which is C-terminally directed. This antibody was raised to pure synthetic neurotensin and detected differences between individual plasma samples of $3 \mathrm{pmol} / 1$ with $95 \%$ confidence. The assay showed no cross-reaction with other gut hormones. As human enteroglucagon is not available in pure form, an indirect radioimmunoassay method was used. Two glucagon antibodies were used, ${ }^{18}$ one of which (R59, N-terminal nonspecific) appeared to cross-react totally with gut glucagon and fully measured pure porcine enteroglucagon (glicentin). The second antiserum RCS5, C-terminal directed appeared to be fairly specific for pancreatic glucagon and gave zero readings in total pancreatectomised patients. The enteroglucagon levels were derived from the difference between these two assays. Changes of $6 \mathrm{pmol} / \mathrm{l}$ were detectable (with $95 \%$ confidence) in this assay system. Plasma gastrin and somatostatin were measured by previously described radioimmunoassays. ${ }^{19} 20$

Statistical analyses were performed using the non-parametric Wilcoxon's rank sum test, but for ease of comparison, mean and standard error of the mean (SEM) are given in the text.

\section{Results}

Mean plasma enteroglucagon concentrations (Table)
Table Plasma enteroglucagon and neurotensin in healthy infants compared with infants with pyloric stenosis

\begin{tabular}{lcl}
\hline & $\begin{array}{l}\text { Enteroglucagon } \\
(\text { pmolll) } \\
(\text { mean } \pm S E M)\end{array}$ & $\begin{array}{l}\text { Neurotensin } \\
(\text { pmol/l) } \\
(\text { mean } \pm S E M)\end{array}$ \\
\hline Controls (30-day) & $190 \pm 17$ & $38 \pm 11$ \\
Pyloric stenosis (30-day) & $84 \pm 8$ & $11 \pm 3$ \\
Control (45-day) & $210 \pm 20 \cdot 5$ & $29 \pm 6$ \\
Pyloric stenosis (45-day) & $82 \pm 22 \cdot 5$ & $13 \pm 2$ \\
\hline
\end{tabular}

in the infants with pyloric stenosis were less than half those of the control infants, at both 30 and 45 days (both $P<0 \cdot 01$ ). These concentrations (both control and pyloric stenosis) by far exceeded the normal adult enteroglucagon concentration $(37 \pm 5 \mathrm{pmol} / \mathrm{l})$.

The neurotensin concentrations (Table) were, similarly, significantly reduced in the infants with pyloric stenosis, at both 30 and 45 days post-partum $(\mathrm{P}<0.01$ and $\mathrm{P}<0.05$ respectively).

The Figure shows the individual enteroglucagon and neurotensin values in the control and pyloric stenosis infants (values at 30 and 45 days were combined). The mean enteroglucagon and neurotensin concentrations in the pyloric stenosis group were significantly $(\mathrm{P}<\mathbf{0 . 0 0 1 )}$ lower than the corresponding control group.

Plasma gastrin and somatostatin concentrations (combined 30 and 45 days) were not significantly different in the two groups (gastrin, $67 \pm 13.5$ and $41 \pm 7 \cdot 5 \mathrm{pmol} / 1$, somatostatin $39 \pm 7$ and $44 \pm 5 \cdot 5$ $\mathrm{pmol} / \mathrm{l}$, in the infants with pyloric stenosis and controls, respectively).

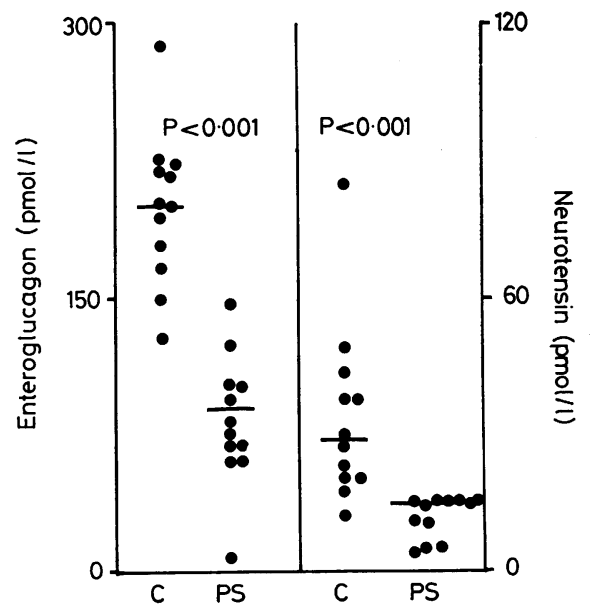

Figure Plasma enteroglucagon (left) and neurotensin (right) concentrations ( $\mathrm{pmol} / \mathrm{l}$ ) in 12 control infants $(C)$ compared with 12 infants with pyloric stenosis $(P S)$. 


\section{Discussion}

There is very limited information regarding plasma concentrations of gut hormones in infantile pyloric stenosis. One hormone (gastrin) however, has received much attention. Although there are many papers on gastrin levels in infants with pyloric stenosis, these are controversial. Several authors have reported raised gastrin ${ }^{12}$ levels whereas others reported no significant differences from control infants. ${ }^{3}{ }^{4}$ Most authorities now accept that gastrin levels in pyloric stenosis are not significantly different, and the results of the present study confirm this view.

Recently we have investigated plasma levels of several gastrointestinal hormones in infants with pyloric stenosis, including motilin ${ }^{21}$ and gastric inhibitory polypeptide. It was found that the upper small intestinal hormones, motilin and gastric inhibitory polypeptide, were significantly lower in the infants with pyloric stenosis. These results, together with the findings of the present study, showing decreased levels of enteroglucagon and neurotensin but similar levels of gastrin and somatostatin, suggest that hormones produced distal to the pyloric sphincter are reduced whereas the proximal hormones are not affected. The reasons for these results are not fully understood. One possible explanation may be the reduced enteral feeding in infants with pyloric stenosis. Thus, because of the pyloric hypertrophy reduced amounts of nutrients reach the intestine which in turn results in understimulation of the gut hormone-producing cells. In contrast, endocrine cells in the stomach are stimulated normally.

We have previously described postnatal surges in the basal concentrations of several gut peptides, including neurotensin ${ }^{22}$ and enteroglucagon. ${ }^{15}$ These increases in hormone levels appeared to be dependent on the presence of nutrients in the alimentary tract. For example, in 6-day-old, preterm babies with hyaline membrane disease, who had been kept on intravenous dextrose since birth, the normal postnatal hormone increase was not seen. These results and those from the present study stress the need for enteral feeding for the maintenance of a normal gut hormone physiology.

The exact physiological functions of enteroglucagon and neurotensin, and indeed the other gut hormones cited above, are not fully defined. Neurotensin and enteroglucagon are thought to play a role in normal gastric motor and secretory function. Enteroglucagon is also thought to exert a trophic influence on the gastrointestinal tract. Alterations in the secretion of these hormones, and also others, may in part explain some of the symptomatology of pyloric stenosis.

We thank the Medical Research Council (UK) for financial support.

\section{References}

1 Spitz L, Zail S S. Serum gastrin levels in congenital hypertrophic pyloric stenosis. J Pediatr Surg 1976; 11: 33-5.

2 Bleicher M A, Shandling B, Zingg W, Karl H W A, Track N S. Increased serum immunoreactive gastrin levels in idiopathic hypertrophic pyloric stenosis. Gut 1978; 19: 794-7.

3 Rogers I M, Drainer I K, Moore M R, Buchanan K D. Plasma gastrin in congenital hypertrophic pyloric stenosis: a hypothesis disproved? Arch Dis Child 1975; 50: 467-71.

4 Moazam F, Rodgers B M, Talbert J L, McGuigan J E. Fasting and postprandial serum gastrin levels in infants with congenital hypertrophic pyloric stenosis. Ann Surg 1978; 188: 623-5.

5 Carraway R, Leeman S E. The isolation of a new hypotensive peptide, neurotensin from bovine hypothalamus. $J$ Biol Chem 1973; 248: 6854-61.

6 Carraway R, Leeman S E. Characterization of radioimmunoassayable neurotensin in the rat, its differential distribution in the CNS, small intestine, and stomach. $J$ Biol Chem 1976; 251 : 7045-52.

7 Polak J M, Sullivan S N, Bloom S R, et al. Specific localisation of neurotensin to the $\mathrm{N}$ cell in human intestine by radioimmunoassay and immunocytochemistry. Nature 1977; 270: 183-5.

8 Blackburn A M, Bloom S R. A radioimmunoassay for neurotensin in human plasma. $J$ Endocrinol $1979 ; 83$ : 175-81.

9 Blackburn A M, Fletcher D R, Bloom S R, et al. Effect of neurotensin on gastric function in man. Lancet 1980 ; $i$ : 987-9.

10 Fletcher D R, Blackburn A M, Adrian T E, Chadwick V S, Bloom S R. Effect of neurotensin in pancreatic function in man. Life Sci 1981; 29: 2157-61.

11 Unger R H, Ketterer H, Eisentraut A M. Distribution of immunoassayable glucagon in gastrointestinal tissues. Metabolism 1966; 15: 865-7.

12 Gleeson $M$ H, Bloom S R, Polak J M, Henry $K$, Dowling $\mathrm{R}$ M. An endocrine tumour in kidney affecting small bowel structure, motility, and absorptive function. Gut 1971; 12: 773-82.

13 Sagor G R, Al-Mukhtur M Y T, Ghatei M A, Wright N A, Bloom S R. Enteroglucagon and intestinal adaptation (abstract). Gut 1981; 22: A439.

14 Bloom S R, Polak J M. Plasma hormone concentrations in gastrointestinal disease. Clin Gastroenterol 1980; 9: 785-98.

15 Lucas A, Adrian T E, Christofides N D, Bloom S R, Aynsley-Green A. Plasma motilin, gastrin, and enteroglucagon and feeding in the human newborn. Arch Dis Child 1980; 55: 673-7.

16 Brazeau P, Vale W, Burgus R, et al. Hypothalamic polypeptide that inhibits the secretion of immunoreactive pituitary growth hormone. Science 1973; 179: 77-9.

17 Bloom S R, Polak J M. Gut hormones. Adv Clin Chem $1980 ; 21$ : 177-244.

18 Ghatei M A, Bloom S R, Enteroglucagon in man. In: 
Bloom J M, Polak J M, eds. Gut hormones, second edition. Edinburgh: Churchill Livingstone, 1981 : 332-8.

19 Bryant M G, Adrian T E. Gastrin. In: Bloom S R, Long $\mathrm{R}$ G, eds. Radioimmunoassay of gut regulatory peptides. Eastbourne: Saunders, 1982: 51-9.

20 O'Shaughnessy D J. Somatostatin. In: Bloom S R, Long R G, eds. Radioimmunoassay of gut regulatory peptides. Eastbourne: Saunders, 1982: 138-45.

21 Christofides N D, Mallet E, Bloom S R. Plasma motilin in infantile pyloric stenosis. Biomed Res 1982; 3: 571-2.
22 Lucas A, Aynsley-Green A, Blackburn A M, Adrian T E, Bloom S R. Plasma neurotensin in term and preterm neonates. Acta Paediatr Scand 1981 ; 70: 201-6.

Correspondence to Professor S R Bloom, Department of Medicine, Royal Postgraduate Medical School, Hammersmith Hospital, Du Cane Road, London W12 0HS.

Received 7 September 1982

\section{Meetings in the UK}

\section{8-19 March 1983, Birmingham}

Paediatric Research Society

Further details: Dr R G Pearse, Jessop Hospital for Women, Leavygreave Road, Sheffield S3 7RE

\section{2-16 April 1983, York}

British Paediatric Association Annual Meeting

Further details: Dr David Harvey, BPA, 23 Queen Square, London WC1N 3AZ

20-24 September 1983, York

International Society for Paediatric Oncology

Further details: Dr C C Bailey, Regional Oncology Unit, Seacroft Avenue, Leeds L14 6UH

10 February 1983, Institute of Child Health, London

8 July 1983, Nottingham

3 November 1983, Institute of Child Health, London

Neonatal Society

Further details: Dr F Broughton-Pipkin, Department of Obstetrics, University of Nottingham, Clifton Boulevard, Nottingham NG7 2UH 